\title{
Oral Myiasis- a Case Report
}

\author{
MAHIMA V GULEDGUD ${ }^{1, *}$, KARTHIKEYA PATIL ${ }^{2}$, ANKITA SAHNI ${ }^{3}$ \\ Department of Oral Medicine \& Radiology, J.S.S. Dental College \& Hospital, Mysore, Karnataka, India \\ *Corresponding author: dr.mahimavg@jssuni.edu.in
}

Received October 31, 2014; Revised November 14, 2014; Accepted November 18, 2014

\begin{abstract}
Myiasis is a rare Dipteria larvae parasitic infestation arising in humans or animals which can invade different parts of the body. Oral Myiais is the rarest form of this rare disease to occur and may be occasionally encountered in developing third world countries owing to poor hygiene due inadequate sanitation amenities. Thorough knowledge of this rare condition aids in early and prompt diagnosis facilitating dimunition of morbidity and mortality. Here we report a case of oral myiasis in 70 year old alcoholic male patient with a neglected mandibular fracture.
\end{abstract}

Keywords: oral myiasis, dipteria species, parasites, maggots, ivermectin

Cite This Article: MAHIMA V GULEDGUD, KARTHIKEYA PATIL, and ANKITA SAHNI, “Oral Myiasis- a Case Report.” International Journal of Dental Sciences and Research, vol. 2, no. 6 (2014): 146-148. doi: 10.12691/ijdsr-2-6-6.

\section{Introduction}

The term myiaisis originally derived from a latin word (Myia meaning Fly and iasis meaning disease) [1,2] was coined by Hope in 1840 and was first described by Lawrence in 1909. [2] It is a pathological condition characterized by infestation of living tissues of humans or animals by Dipteria larvae. These larvae feed on living or dead necrotic tissue of the host and develop as parasites. [2] Human myiasis is rare and has been mostly encountered in regions with warm and humid climate [3].

Clinically myiasis has been classified into primary and secondary myiasis depending on whether they feed on living or dead tissue. [4,5] They can also be classified into obligatory and facultative type depending on the condition of the involved tissue. [6] Eighty different species of dipteria have been known to invade humans and may affect different parts of human body like eyes, ears, nose, vagina, skin. However, oral involvement is very rare. [3] We report a case of oral myiaisis in a 70 year old alcoholic male patient with a neglected mandibular fracture.

\section{Case Report}

A 70 year old disoriented male patient belonging to low socioeconomic status and a chronic alcoholic by habit reported to us with a complaint of noticing a painless swelling on left side of the face since 2 weeks. Patient gave history of gradual and constant increase in the size of swelling to attain the present size. Swelling was associated with difficulty in mouth opening and functional jaw movements since 10 days. Patient's attender gave history of noticing a fetid order from the patient along with reduction in appetite and weight. History revealed an episode of self fall (under the influence of alcohol) 4 years back following which the patient had undergone open reduction with archbar fixation in a general hospital. Due to financial restraints patient did not report for follow up and the treatment remained incomplete.

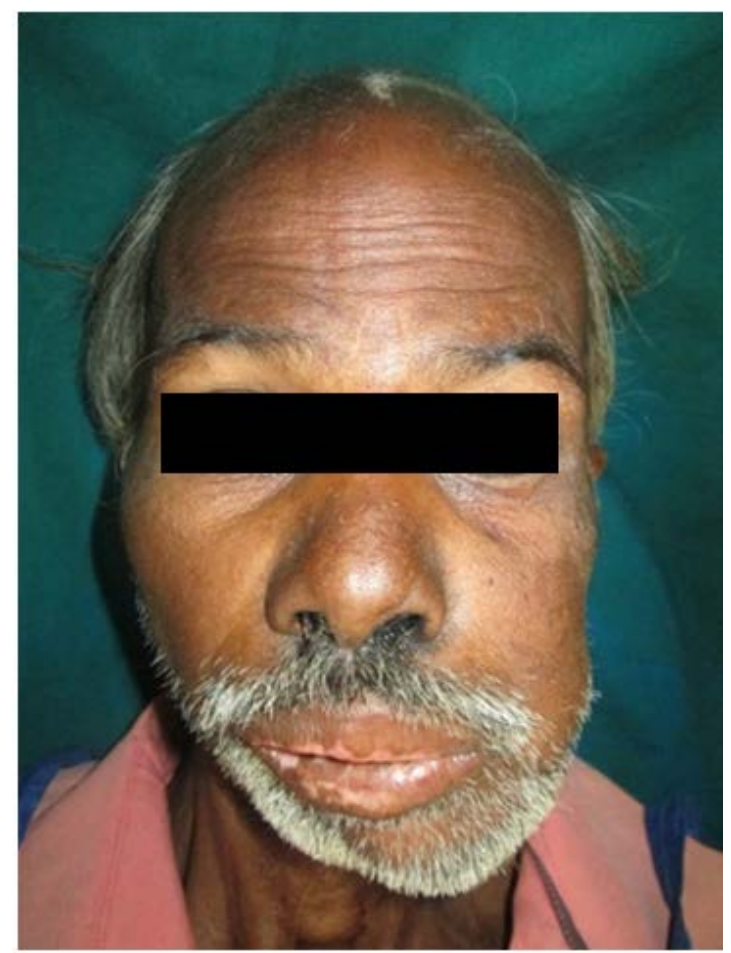

Figure 1. Extra oral photograph of the patient showing a swelling roughly measuring about $3 \times 5 \mathrm{~cm}$ on left body of the mandible

On general physical examination he was found to be moderately built and poorly nourished with an unsteady gait. His pulse rate, respiratory rate and blood pressure were found to be below the normal range. On extraoral examination a swelling roughly measuring approximately about 3 X $5 \mathrm{~cm}$ was noted on left side of the body of the 
mandible. On the inferior aspect of the mandible a perforation measuring about $3.5 \times 2 \mathrm{~cm}$ was noted along with numerous crawling live maggots and necrotic tissue. Due to inability to open the mouth a thorough and complete intraoral examination was not possible. Poor oral hygiene and severe halitosis were evident though (Figure 1 and Figure 2).

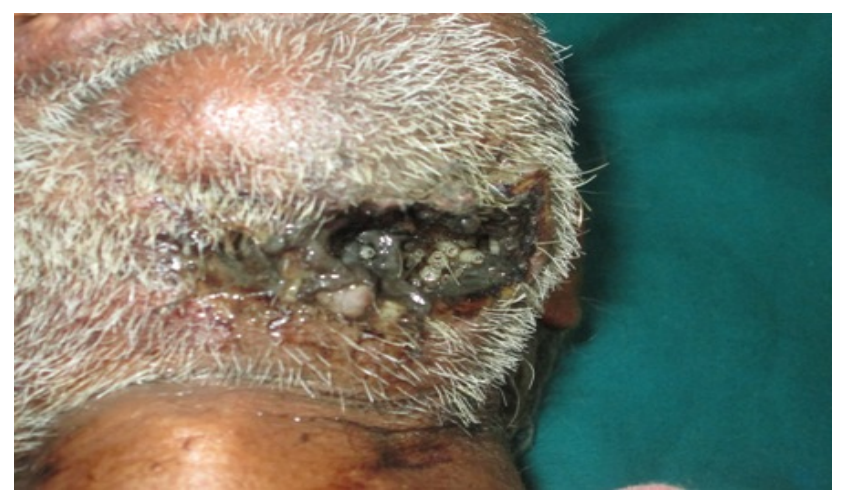

Figure 2. Inferior aspect of the swelling showing a mandible a perforation measuring about $3.5 \times 2 \mathrm{~cm}$ was noted along with numerous crawling live maggots and necrotic tissue
On the basis of history and clinical findings a diagnosis of Oral Myiasis was made. Patient was referred to department of oral and maxillofacial surgery for emergency management.

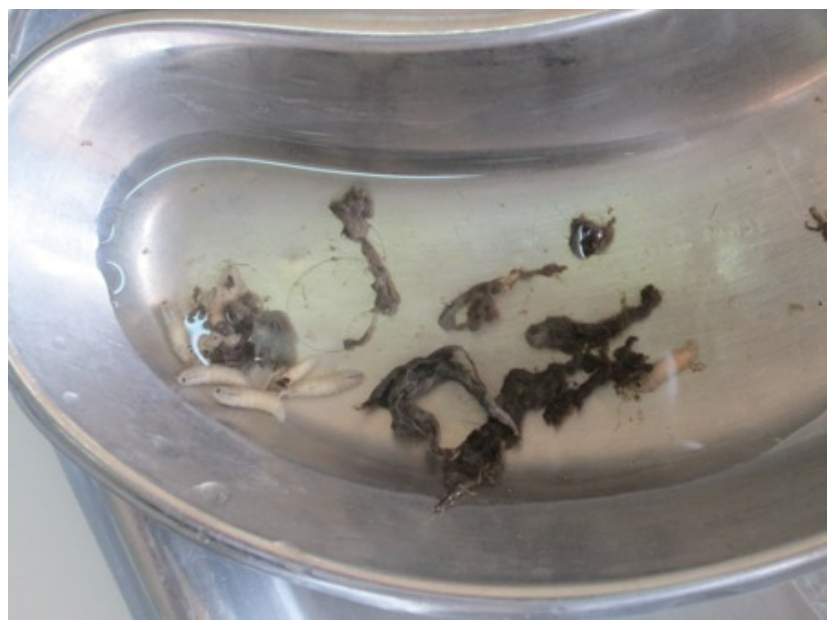

Figure 3. After manual removal of maggots following application of turpentine oil

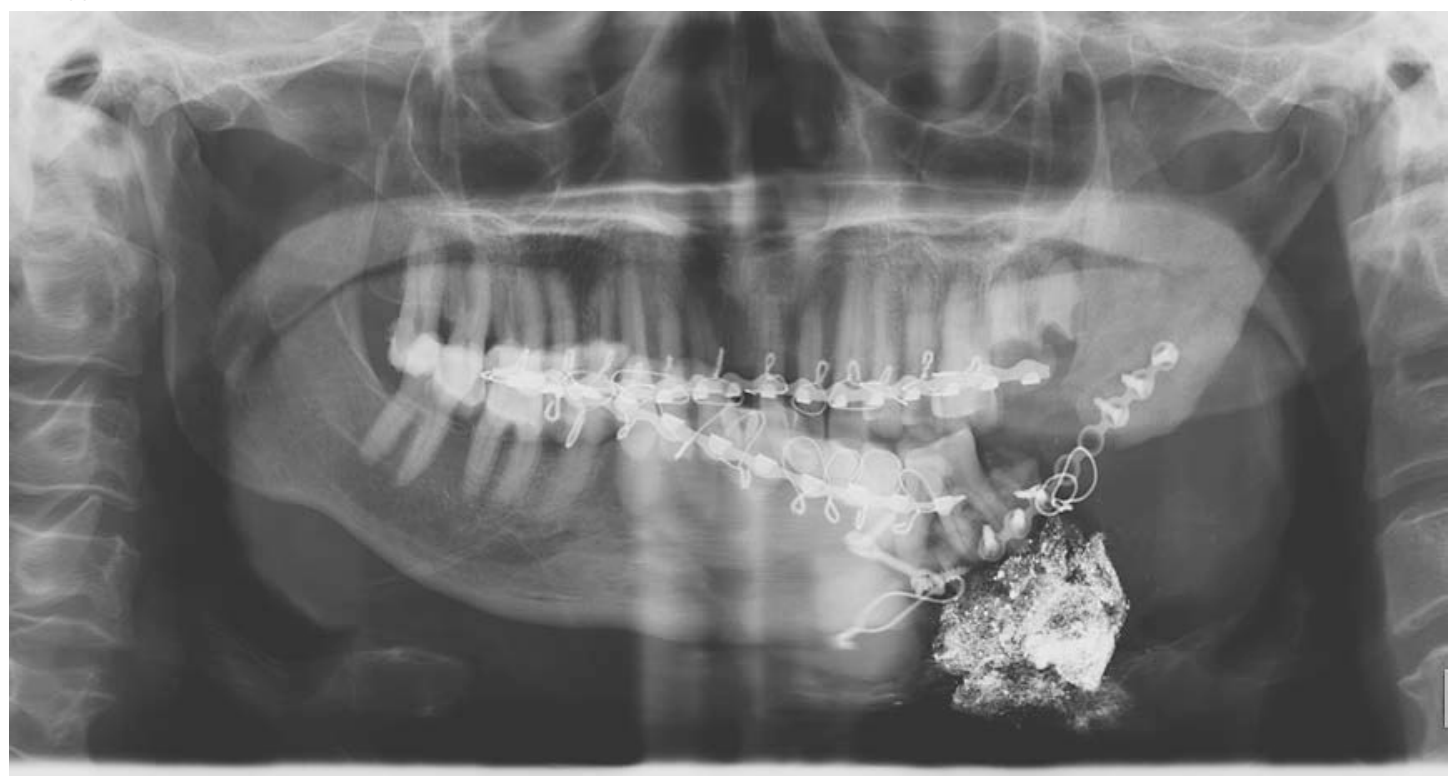

Figure 4. Orthopantamograph showing considerable loss of body of the mandible on left side. Radiopacity due to the presence of BIPP (Bismuth Iodine Parrafin Paste) Pack

Patient underwent manual removal of maggots after application of turpentine oil and surgical debridement of dead necrotic tissue followed by BIPP pack placement (Bismuth Iodine Parrafin Paste). (Figure 3) Further, an orthopantamograph was made, which showed considerable loss of body of the mandible on left side (Figure 4).

Patient was administered with Tab Ivermectin 6mg once daily for two days along with Injection Cefazolin 1 gm every 6 hourly and Inj. Metronidazole 500 mg every 8 hourly for five days. However, 2 days later patient withdrew from treatment against the consent of hospital authorities and was lost to follow up.

\section{Discussion}

Oral myiasis was first described by Lawerence in 1909. [1] It is an uncommon disease in humans with most cases reports from tropical rural areas like South East Asia,
China, Indian subcontinent, Tropical Africa, and Papua New Guinea. [7] In literature males have been found to be more commonly infested than females which is in agreement with the finding of the present case [8].

Oral myiasis has been found to be associated with alcoholism, mental retardation, trauma and poor oral hygiene. Predisposing factors like diabetes and peripheral vascular diseases may facilitate in the development of myiasis. [3] Human infestation by maggots may occur by two ways, either by direct inoculation or by ingestion of infected material like meat. Eitan Bar Droma et al in their review of literature on oral myiaisis found most cases to be from tropical countries with only two cases from the Indian subcontinent and majority of the patients were found to be associated with some underlying predisposing factor. They also found anterior part of the oral cavity to be the most common location of the lesion suggesting direct inoculation of the tissues (Table 1) [8]. 
Table 1. Cases reviewed by Eitan Dan Droma et al [8]

\begin{tabular}{|c|c|c|c|}
\hline Patient age/Sex & Country & Underlying disorder & Location of the lesion \\
\hline 12 years/Male & India & Incompetent lips, poor oral hygiene & Gingiva of anterior mandible \\
\hline 45 years /Male & India & Malnourished,mandibular fracture & Lips and floor of the mouth \\
\hline 3 years/Male & Iran & None & Gingiva of anterior maxilla \\
\hline 26 years/Male & Turkey & Mouth breather & Gingiva of anterior maxilla \\
\hline 20 years/Female & Brazil & Hypotonic cerebral palsy & Gingiva of anterior maxilla \\
\hline 66 years/Female & Brazil & Advanced periodontal disease & Gingiva of anterior maxilla \\
\hline 89 years/Female & Hongkong & Pulmonary Tuberculosis,Feeding by nasogastric tube & Gingiva of anterior maxilla \\
\hline 24 years/Male & Brazil & After Extraction & Gingiva of anterior maxilla \\
\hline 36 years/ Female & Turkey & Advanced periodontal disease & Gingiva of anterior maxilla \\
\hline 69 years/Male & Israel & Advanced periodontal disease & Gingiva of anterior maxilla \\
\hline 19 years /Male & Israel & None & Gingiva of posterior mandible \\
\hline
\end{tabular}

In the present case patient was an alcoholic belonging to low socioeconomic status with poor sanitary conditions. An untreated maxillofacial trauma in conjugation with above conditions acted as predisposing factors.

The dipteria flies lay egg in living or necrotic tissue which later hatch to form maggots which over a period of two weeks turn into flies to complete their lifecycle. [3] The larvae are usually photophobic and tend to burrow deep into the tissue. Early diagnosis of this condition prevents deeper involvement [6].

Clinically it usually manifests as an erythematous swelling with an area of perforation enclosed with numerous m larvae and necrotic tissue. It may or may not be associated with pain. This is in accordance with the clinical manifestation of the present patient [6].

Traditional method of management of a patient with myiasis includes mechanical removal of larvae along with turpentine oil which aids in blocking their respiratory sinuses and forces them to emerge on the surface resulting in an increase in their accessibility. Ether, iodoform and choloroform are the other such agents which can be used. [8,9] Recently systemic ivermectin has been tried in many patients with successful results. [10] Ivermectin is a semisynthetic macrolide antibiotic, obtained from Streptomyces avermitilis. [11] It is the only antibiotic which has been found to effective against maggots. It can be administered via oral or intravenous route. Mechanism of action is through blocking nerve impulses on the nerve endings of the larvae through the release of gamma aminobutyric acid (GABA) and linking to the receptors, causing palsy and death [10]. It has been found to be a safe drug with no adverse renal or hepatic dysfunctions. In severe cases it is usually administered orally in doses of $150-200 \mathrm{mg} / \mathrm{kg}$ body weight. However, Gealh reported failure of complete elimination of maggots even with high dose administration for duration of 5 days. [11] Our patient was managed with manual debridement and administration of systemic ivermectin along with an antibiotic coverage. However, patient withdrew from treatment and was lost to follow up.
Worldwide civilization and development has reduced the chances of encountering a patient with myiasis. However, it may be encountered occasionally in developing third world countries due to scarce sanitation amenities. Even though oral myiasis is the rarest form of this rare condition, oral health care practioners should be well aware of this infestation as early diagnosis can prevent deeper penetration facilitating diminution of morbidity and mortality.

\section{References}

[1] Sheikh S, Pallagatti S, Singla I, Kalucha A, Aggarwal A, Kaur H. Oral Myiasis- A review. J Clin Exp Dent. 2011; 3(5): e465-8.

[2] Pramod kumar,Sri Kumar G P V.Oral Myiasis in a maxillofacial trauma patient Contemporary Clinical Dentistry April- June 2012 3(2): 202-204.

[3] Bhavana Agrawal, Apeksha Dhole, Savita Deora Bhavana Agrawal Oral Myiasis: A Case Report Int J Dent Case Reports 2012; 2(3):61-65.

[4] Sowani A, Joglekar D, Kulkarni P: Maggots. A neglected problem in palliative care. Indian J Palliat care 10(1): 27-29, 2004.

[5] Gomez RS, Perdigao PF, Pimenta F, Riosleite AC et al: Oral Myiasis by screwworm cochlimyia hominivorax. $\mathrm{Br} \mathrm{J}$ Oral Maxillofac Surg 2003; 41: 115-116.

[6] Bhatt AP, Jayakrishna A: Oral Myiasis. A case report. Int J Pediatric dent 2000; 10; 67-70.

[7] Ng KH, Yip KT, Choi CH, Yeung KH, Auyeung TW, Tsang AC et al. A case of oral myiasis due to Chrysomya bezziana in Hong Kong. Hong Kong Med J. 2003; 9; 454-6.

[8] Droma EB, Wilamowski A, Schnur H, Yarom N, Scheuer E, Schwartz E. Oral myiasis: a case report and literature review. Oral Surg Oral Med Oral Path Oral Radiol Endod 2007; 103(1): 92-6.

[9] Nitin Verma, Jayant Marya Oral Myiasis In Maxillofacial Trauma - Treated With Ivermectin International Journal Of Dental Clinics 2011: 3(2): 97-98.

[10] Shinohara EH, Martini MZ, de Oliveira Neto HG, Takahashi A. Oral myiasis treated with Ivermectin: Case Report. Braz Dent J 2004; 15:79-81.

[11] Khan Muslim, Mehboob Bushra, Wahab Ul Noor,Mansoor Nadia Oral myiasis: a case series of 11 patients treated at Khyber College of Dentistry hospital, Peshawar Pakistan Oral \& Dental Journal 2014: 34(1): 57-60.

\section{Conclusion}

